\title{
NOTAS SOBRE Pholus vitis (L., 1758) (Lep., Sphingidae)
}

\author{
LUIZ GONZAGA E. LORDELLO \\ (Assistente da Cadeira de Zoologia da Escola Superior de Agricultura \\ "Luiz de Queiroz" da Universidade de São Paulo)
}

A literatura entomológica econômica do Brasil, tendo à frente c Catálogo do Prof. COSTA LIMA (1936), registra diversas espécjes de Lepidópteros da família Sphingidae, cujas lagartas desenvolvem-se à custa da folhagem da videira (Vitis vinifera L.).

Nesta região de Piracicaba (Estado de São Paulo), a primeira espécie por nós verificada sôbre a planta referida, foi Enyo ccypete (L., 1758), da subfamília Sesiinae.

Em janeiro de 1952, obtivemos mais lagartas, sempre encontradas isoladas e de difícil localização no interior da densa folhagem que cobre as plantas nessa época do ano. Os excrementos que caem ao solo auxiliam a busca, dando-nos mais ou menos a posição do inseto.

Desta vez, obtivemos outra espécie que, a nosso pedido, o Naturälista J. Oiticica Filho, do Museu Nacional, identificou como Pholus vitis (Linnaeus, 1758) (Fig. 1).

A espécie figura entre as mais comuns da subfamília $M a-$ croglossinae, sendo difundida no Brasil e em outros Países da América. 
GOMES da COSTA (1944) e BIEZANKO (1948) constataram-na no Rio Grande do Sul; MONTE (1934) também a obteve $\mathrm{em}$ Minas Gerais e OITICICA FILHO (1939) determinou-a dentre o material de Sphingidae obtido durante a Excursão Científica do Instituto Oswaldo Cruz pela zona da Estrada de Ferro Noroeste do Brasil.

HOFFMANN (1942) verificou a sua ocorrência em todo o Sul do México e HAYWARD (1942) assinalou suas larvas sôbre a videira, na Argentina.

Damos uma descrição da lagarta a têrmo dêste curioso $M a$ croglossinae (Fig. 2).

“Coloração geral verde clara. Cabeça pequena, sem brilho, verde relativamente escuro; mandíbulas negras. Protórax verde mais claro que a cabeça. Meso e metatórax de um tom esverdeado ainda menos intenso, com laivos amarelos e ornados por pontuações negras, particularmente abundantes no metatórax. O 1.o, 2.o, 3.o e 4.o segmentos abdominais também mostram matizes amarelados e pontilhações escuras, máxime o 1,o. No 3.o e 4.c segmentos, a ornamentação resume-se em dois pontos pretos por segmento, localizados no dorso. No metatórax e nos dois segmentos seguintes aparecem também pontuações negras ventrais.

$O$ dorso de todo o abdômen é de um verde fosco, com pontuações amarelas. Do 1.o ao 7.o segmento, ao longo do corpo, destaca-se uma fita mais escura, correspondente ao vaso dorsal. Nas faces laterais do corpo, a coloração verde tende francamente ao amarelc, mostrando numerosos pontos dessa côr.

Os estigmas são rosados, elípticos e bem visíveis. Pelo estigma passa uma faixa oblíqua amarela, bem evidente nos segmentos 4 a 7 . Os segmentos 1 a 3 possuem-na apenas levemente. Além do 7.0 segmento, não se observa a fita referida.

Tôdas as patas mostram coloração verde. As abdominais são tingidas de negro na extremidade distal, com um laivo amarelo localizado na face externa, próximo da ponta.

Comprimento : $80 \mathrm{~mm}$ ".

Terminado o período de vida larvária, a lagarta emigrou para c fundo da gaiola, pondo-se a caminhar nervosamente, se- 
guindo as paredes internas e deixando, sôbre a areia úmida, o sinal das caminhadas efetuadas. Tocada, punha-se imóvel por algum tempo, recolhendo a cabeça e adquirindo, em parte, a atitude característica dos membros da família a que pertence. O corpo apresentava-se endurecido, mantendo-se reto quando suspenso pela sua porção mediana.

A coloração sofre alterações, a região média dorsal adquirindo tonalidades rosadas, conservando-se claras as uniōes dos segmentos. As fitas amarelas dos flancos tornam-se apagadas, persistindo, embora pouco nítida, a pontilhação escura a que nos referimos. O vaso dorsal continúa bem visível, como uma fita Escura ao longo do corpo.

De início, a lagarta enterrou-se no substrato do viveiro onde era mantida, vindo, contudo, a sofrer a ninfose na superfície, completamente desprotegida.

A medida que se aproximava o momento da transformaçãn, os tons rosados foram desaparecendo, de modo que a prépupa apresentou-se perfeitamente verde.

A pupa, com $55 \mathrm{~mm}$ de comprimento, ao emergir da última pele, também é inteiramente verde clara, tornando-se, em pouco tempo, marrom escura, com pouco brilho. Molestada, movese ativamente com os quatro últimos urômeros.

A vida pupal durou cêrca de 21 dias.

\section{SUMMARY}

The Brazilian entomological literature mentions some species of Sphingidae living on Vitis vinifera leaves, one of which is Pholus vitis (Linnaeus, 1758), of the subfamily Macroglossinae.

The last instar caterpillar as well as the pupa are described in this note, some biological informations being also given.

\section{LITERATURA CITADA}

BIEZANKO, C. M. de, 1948 - Sphingidae de Pelotas e seus arredores (Contribuição ao conhecimento da fisiografia do Rio Grande do Sul). Publ. esparsa, pág. 1-8, Pelotas, Rio Grande do Sul. 
COSTA LIMA, A. M. da, 1936 - Em Terceiro Catalogo dos Insectos que vivem nas plantas do Brasil, pág. 1-460 + I-IV, Dir. de Estatística da Produção, Rio de Janeiro.

GOMES da COSTA, Ramiro, 1944 - Pragas das plantas cultivadas do Rio Grande do Sul. Public. da Sec. de Inf. e Prop. Ágríc. (Porto Alegre) 103 : 1-136, fig. 1-147.

HAYWARD, Kenneth J., 1942 - Primera lista de Insectos Tucumanos perjudiciales. Public. misc. de la Est. Exp. Agric de Tucuman (Argentina) 1: 1-110.

HOFFMANN, Carlos C., 1942 - Catalogo Sistematico y Zoogeografico de los Lepidopteros Mexicanos. Tercera parte: Sphingoidea y Saturnioidea. An. del Inst. de Bio. (Mexico) 13 : 213-256.

LORDELLO, Luiz Gonzaga E., 1951 - Nota sôbre Enyo ocypete (Linnaeus, 1758) (Lep., Sphingidae). Rev. de Agric. (Piracicaba) 26(9-10): 299-302, fig 1-2.

MONTE, O., 1934 - Borboletas que vivem em plantas cultivadas. Public., Série Agric., da Secretaria da Agric. (Belo Horizonte) 21: 1-220, fig. 1-168.

OITICICA FILHO, J., 1939 - Sphingidae. Em "Relatório da Excursão Científica do Instituto Oswaldo Cruz realizada na zona da Estrada de Ferro Noroeste do Brasil". Bol. Bio. 4, n. s., (2) : 269-277. 


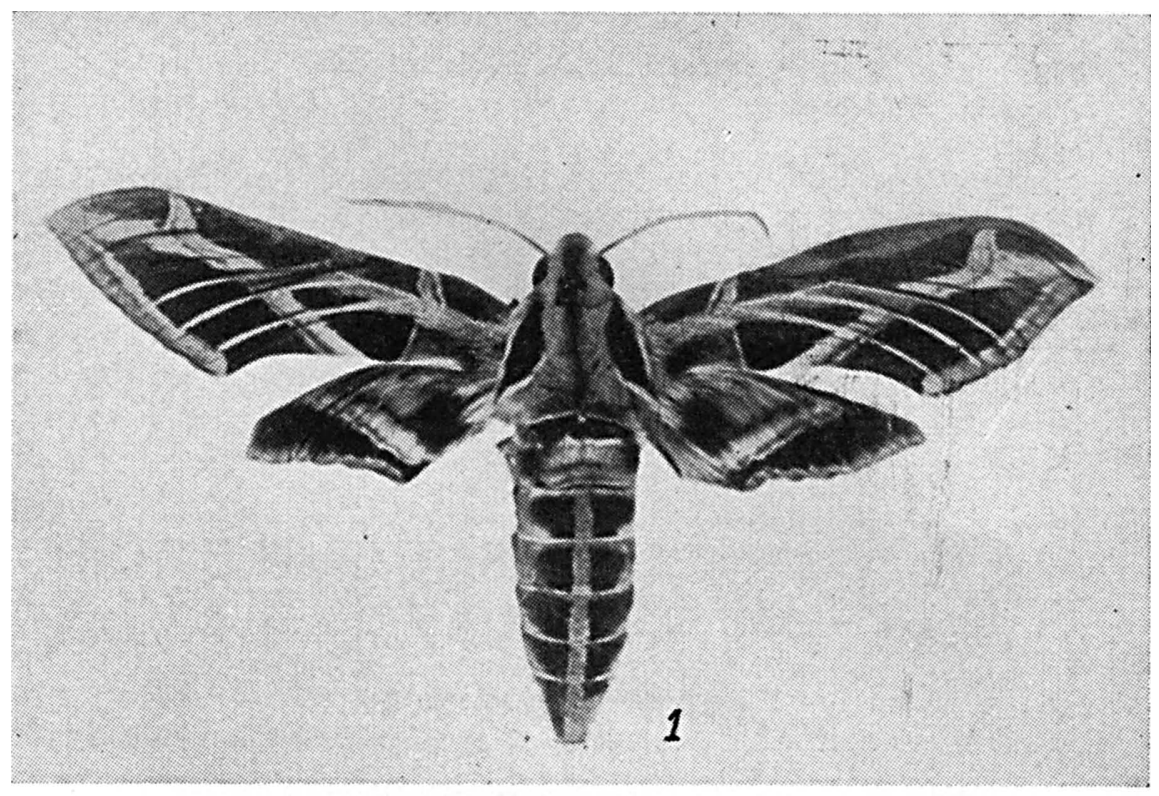

Fig. 1 - Pholus vitis (Linnaeus, 1758). (Fêmea)

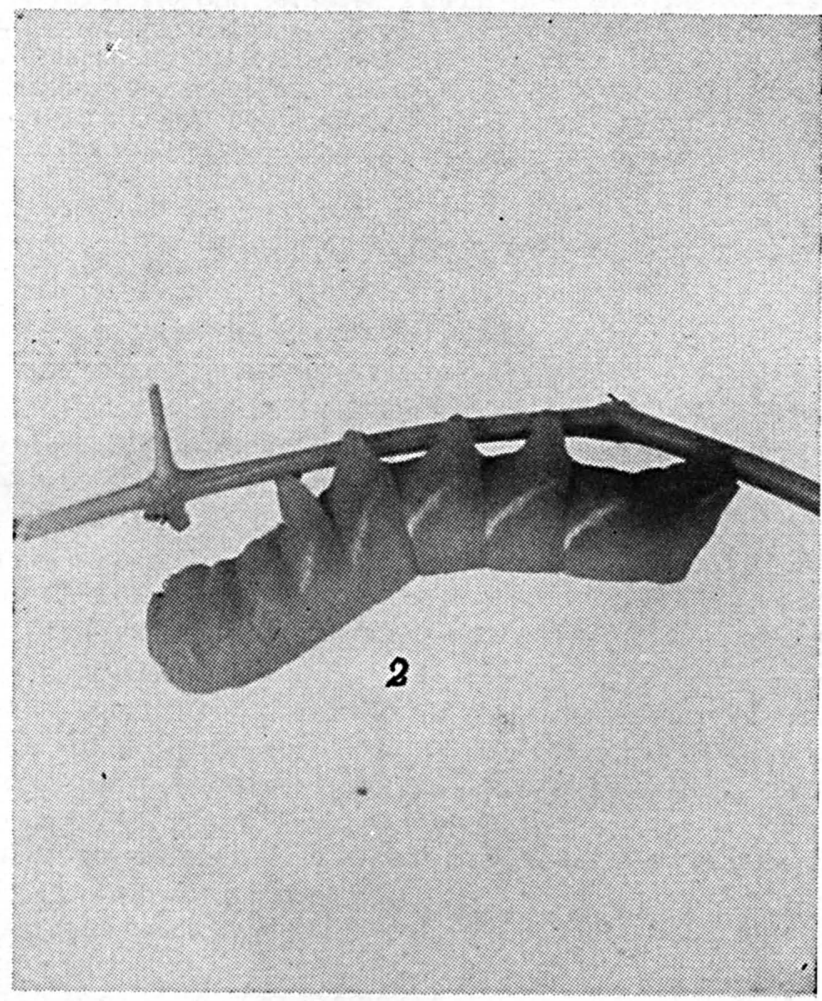

Fig. 2 - Pholus vitis (Linnaeus, 1758). (Lagarta adulta) 